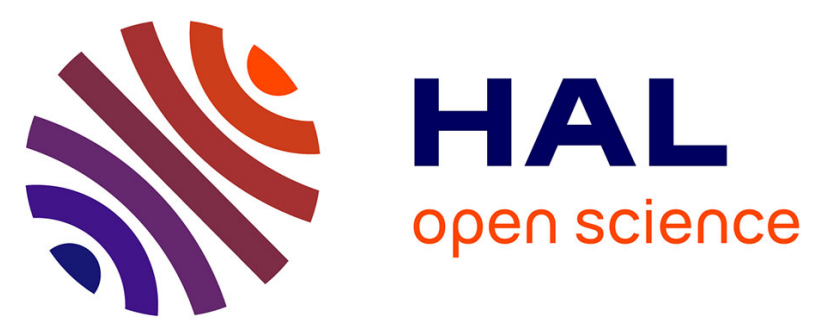

\title{
Self-lubricating composite bearings: Effect of fibre length on its tribological properties by DEM modelling
}

Maria Villavicencio, Mathieu Renouf, Aurélien Saulot, Yann Michel, Yves Mahéo, Guillaume Colas, Tobin Filleter, Yves Berthier

\section{- To cite this version:}

Maria Villavicencio, Mathieu Renouf, Aurélien Saulot, Yann Michel, Yves Mahéo, et al.. Selflubricating composite bearings: Effect of fibre length on its tribological properties by DEM modelling. Tribology International, 2017, 113, pp.362 - 369. 10.1016/j.triboint.2016.12.022 . hal-01555615

\section{HAL Id: hal-01555615 https://hal.science/hal-01555615}

Submitted on 4 Jul 2017

HAL is a multi-disciplinary open access archive for the deposit and dissemination of scientific research documents, whether they are published or not. The documents may come from teaching and research institutions in France or abroad, or from public or private research centers.
L'archive ouverte pluridisciplinaire HAL, est destinée au dépôt et à la diffusion de documents scientifiques de niveau recherche, publiés ou non, émanant des établissements d'enseignement et de recherche français ou étrangers, des laboratoires publics ou privés. 


\title{
Self-lubricating composite bearings: Effect of fibre length on its tribological properties by DEM modelling
}

\author{
M.D. Villavicencio ${ }^{\mathrm{a}, \mathrm{b}, \mathrm{c}, \mathrm{d}}$, M. Renouf ${ }^{\mathrm{b}, \mathrm{f}}$, A. Saulot $^{\mathrm{a}, \mathrm{f}, *},{\text { Y. } \text { Michel }^{\mathrm{c}}, \text { Y. Mahéo }^{\mathrm{d}} \text {, G. Colas }}^{\mathrm{e}}$, T. Filleter ${ }^{\mathrm{e}}$, Y. Berthier $^{\mathrm{a}, \mathrm{f}}$ \\ a LaMCoS, Université de Lyon, INSA-Lyon, CNRS, Villeurbanne, France \\ b LMGC, Université de Montpellier, CNRS, Montpellier, France \\ c CNES, 18 avenue Edouard Belin, 31401 Toulouse Cedex 9, France \\ d SKF Aerospace, F-26300 Châteauneuf-sur-Isère, France \\ e Department of Mechanical and Industrial Engineering, University of Toronto, Toronto, Canada \\ ${ }^{\mathrm{f}}$ InTriG, International Tribology Group, Villeurbanne, France
}

Self-lubricating polymer-based composites are used in space and in aircraft mechanisms as materials for solid lubricated systems. Such composites mostly consist of a polymeric matrix and fillers of two kinds: hard fillers (fibres made of glass, or of minerals) and solid lubricating particles (made of $\mathrm{MoS}_{2}$ ). Their advantages are that they provide their own lubrication, and they can be used in both very high and very low temperatures (from -40 up to $\sim 200 \mathrm{~F}$ ).

Precision ball bearings with these composites are manufactured since the 60's in these bearings the retainer material itself provides the lubrication. From the experimental analyses implemented (X-ray tomography, SEM observations, and experiences in a tribometer); it is possible to observe that the geometry of the fillers has a strong influence on the third body rheology. Nevertheless, the confined nature of the contact does not allow in-situ observation.

To overcome this difficulty a combined numerical/experimental approach is carried out. To be able to reproduce the evolution of third-body particles within the contact, Discrete Element Methods (DEM) is used. Such an approach allows to represent wear: by the construction of an equivalent continuous medium resulting from the incorporation of interaction laws between the discrete particles.

The motivation to this work is the understanding of the impact of filler geometry o tribological behaviour of these materials. More specifically, the goal is to study the influence of the fibre length in the tribological behaviour of self-lubricating composites by Discrete Element Methods (DEM).

Keywords:

Self-lubricating material

Composites

Bearing

Space tribology

DEM

\section{Introduction}

In space mechanisms, a solid lubricant can be utilized as a coating on the tribological surface, or inside a composite material. For ball bearings in space mechanisms, a combination of the two methods is often used: in the first method a coating is applied to the races and balls; while in the second, the cage itself is made of the self-lubricating composite [1]. This self-lubricant is transferred to the balls and races, by a mechanism called double-transfer [2]. In the double transfer mechanism the cage is constituted of the self-lubricating material, while the rest of the bearing is in metal. The cage transfers elements of its material to the ball which, successively, transfer material to the inner and outer races (see Fig. 1). This process acts to limit wear by the regeneration of lubricant coating coming from cage wear. Moreover, it allows to increase the lifetime of the mechanism [3]. Some examples among self-lubricating composites based on polymers dedicated to space applications are RT/Duroid 5813 [3,4] and PGM-HT [3,4], which are both based on Polytetrafluoroethylene (PTFE), or Vespel-SP3 [1,5], Sintimid and Tecasint, based on polyimide $[1,5]$.

The tribological behaviour of self-lubricating composites is especially studied since the production of the RT/Duroid 5813, a composite benchmark, has been ceased [1,3,5]. Although few information is available in literature about the exact composition of RT/Duroid 5813, as PGM-HT, it is made of PTFE (matrix), glass fibres, and $\mathrm{MoS}_{2}[1,3,4,5]$.

In the works of Sicre et al. [3], the tribological performance of the

\footnotetext{
* Corresponding author

E-mail addresses: aurelien.saulot@insa-lyon.fr (A. Saulot), aurelien.saulot@insa-lyon.fr (Y. Berthier).
} 
(a)

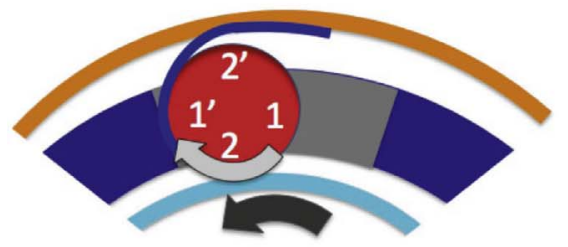

(b)

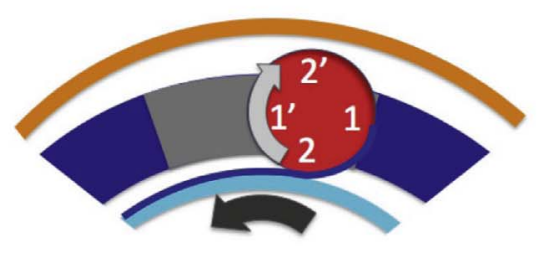

External Race

Internal Race

Ball

Cage

Transfer Film

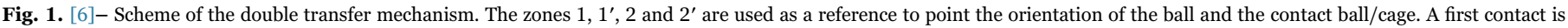

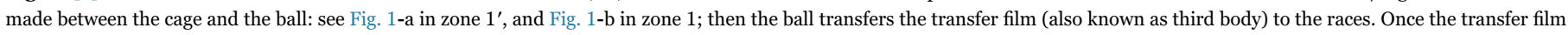
is on the ball, it can be transferred at any time on the races when entering the contact ball/race.

PGM-HT is studied in order to replace the RT/Duroid 5813. They compare the microstructures of these composites, under the consideration that their compositions are similar in ingredients and in proportions. They observe that PGM-HT's microstructure is coarser than the RT/Duroid 5813's one. Moreover, they underline the fact that the differences in their morphologies may have an influence in the release of wear particles, as well as their size within the contact: the coarse PGM-HT microstructure leads to big particles compared to those generated by RT/Duroid 5813.

Furthermore, after carrying out tribological tests, they observe that, contrary to RT/Duroid 5813, PGM-HT cages are unable to release $\mathrm{PTFE} / \mathrm{MoS}_{2}$ particles in order to create a sufficient transfer film. They perceive that while RT/Duroid 5813 can be considered as a good lubricant, being a material able to create a stable PTFE/ $\mathrm{MoS}_{2}$ transfer film, no transfer film is observed in PGM-HT caged bearings.

Merstallinger et al. [1,5] propose a study on the lubrication mechanisms of PTFE-based composites and on the development of a new composite to fulfil needs by space applications. They design a variety of composites, with different compositions (including composites based on PTFE/ $\mathrm{MoS}_{2} /$ Glass Fibre), and different size of fillers. They observe different tribological behaviours in composites with larger and smaller fibres. Likewise, they perceive a dependence of load on friction, for composites with larger fibre diameter. Furthermore, Colas et al. [2] work on the experimental reproduction of the double transfer mechanism on a dedicated environmental tribometer, and on the investigation of self-lubricating materials. They observe that fibres are shown to have a sensible impact in controlling both the trapping of third body particles needed to form the transfer film, and the film's cohesion. Moreover, they see that efficient lubrication at the ball/cage interface appears when a powdery and mobile third body, is created in the retainer/ball contact, and is trapped inside the contact thanks to the fibres.

However, despite that the importance of the composite microstructure on the tribological performances is pointed out [1-5], the role and impact of the different constituents on the degradation and lubrication mechanism are not yet well understood. Thus, in the present work, it is proposed the development of a methodology resulting from the combination of numerical and experimental approaches, in view to anticipate the tribological behaviour of future composite materials, and to underline the impact of fibre length on the tribological behaviour. This methodology is an alternative to the creation of a new material, developed so far through a fully experimental trial and error process, long and costly. As the numerical simulation should be able to represent the local evolution of the contact, the framework of Discrete Element Methods (DEM) is used. Indeed, contrary to classical Finite Element Approach, such a model allows to describe the tribological circuit of a contact in terms of both material flows and porosity $[7,8]$. Experimental analyses are carried out to identify the differences in the microstructures and compositions of both RT/Duroid 5813 and PGM-HT, and also to feed the different numerical parameters. Constituent data are obtained experimentally by SEM, by X-ray Tomography and by image analysis as shown in Section 2. Then, model hypotheses are presented and are related to experimental observations in Section 3. Finally, the results obtained by DEM simulations are shown in Section 4.

\section{Composites observations and composition analyses}

Samples of the self-lubricating materials used for observation are cylindrical, and have a length of $12 \mathrm{~mm}$, and a diameter of $7 \mathrm{~mm}$. Two materials are observed:

- RT/Duroid 5813, produced by Rogers Corporation (USA) (and whose production ceased in the 90's);

- PGM-HT, produced by JPM Mississippi (USA).

\subsection{Observations by X-ray tomography}

In order to build a realistic 3D image of the microstructure of the self-lubricating materials, an X-ray tomography High resolution (type tomograph RX Solutions EasyTom Nano - maximum resolution of $0.7 \mu \mathrm{m}$ per pixel) is conducted on samples of each composite (Fig. 2) of $0.5 \times 0.5 \times 0.5 \mathrm{~mm}^{3}$ (samples are cut at room temperature). Then $3 \mathrm{D}$ volumes were reconstructed through the ImageJ software and its extension Fiji. Under X-ray, the white areas indicate the presence of $\mathrm{MoS}_{2}$, light grey areas indicate the presence of glass or mineral fibres (according to the composite), and the black areas are related to the PTFE matrix.

A threshold tool is used to segment the grey scale images into the features of interest: the white, the light grey and the black areas. Among the different threshold methods provided by Image $J$; three of them were selected ("RenyiEntropy", "Moments" and "Otsu" [9]). The threshold methods chosen are those that discriminated the grey scale images in a better way: delimiting with exactitude the white, the light grey and the black areas. Then, these threshold techniques are utilized to determine the volume fraction of the different constituents.

Similar results of volume fraction are obtained irrespective of the analytical technique used. As a consequence, only one technique among the three is chosen to measure the volume fraction of each component. Each imaged plan in X-ray tomography (Fig. 3-a) is processed by the thresholding technique "Moments" [9] (Fig. 3-b). Different sizes of windowing (elemental analysis area) are used to analyse the proportion of each component within each plane (Fig. 3-c) and for the total number of plans (equal to 1000 plans in this analysis) (Fig. 3-d).

The analysis of images by high-resolution X-ray tomography enables to separate the $\mathrm{MoS}_{2}$ (white) of the remaining components for each composite (black to grey). The volume fraction of $\mathrm{MoS}_{2}$ $\left(\phi \mathrm{MoS}_{2}\right)$ as well as the addition of volume of fibre and $\mathrm{MoS}_{2}$ ( $\phi$ Fibre $+\phi \mathrm{MoS}_{2}$ ), can be determined directly by image analysis. Nevertheless, the analysis of images by high-resolution X-ray tomography did not enable to separate the fibres (light grey) because of the similar colour of the fibre and matrix in the image analysis, and the volume fraction of the fibre cannot be determined directly. Assuming that the material did not have a significant degree of porosity compared to the percentage of measured elemental constituents ( $\mathrm{MoS}_{2}$, PTFE and fibres) it is possible to express the volume fraction of fibres as it is shown in the following expression, 

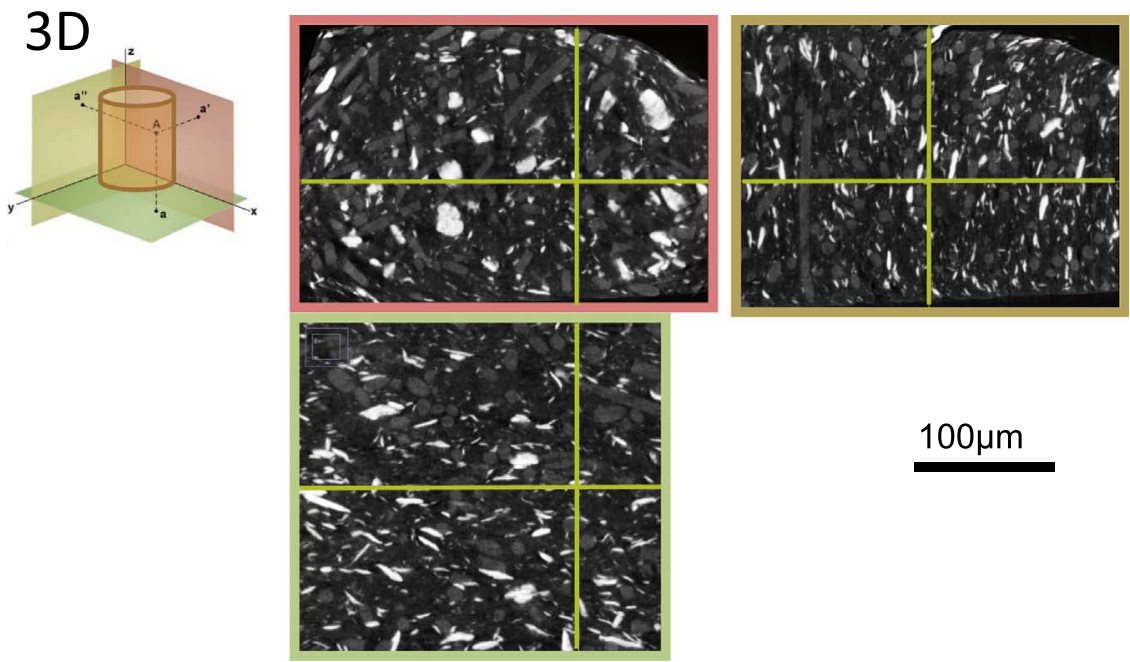

$100 \mu \mathrm{m}$

Fig. 2. Images obtained by X-ray tomography of a PGM-HT (white: $\mathrm{MoS}_{2}$, light grey: fibre, dark grey: PTFE (Matrix)).

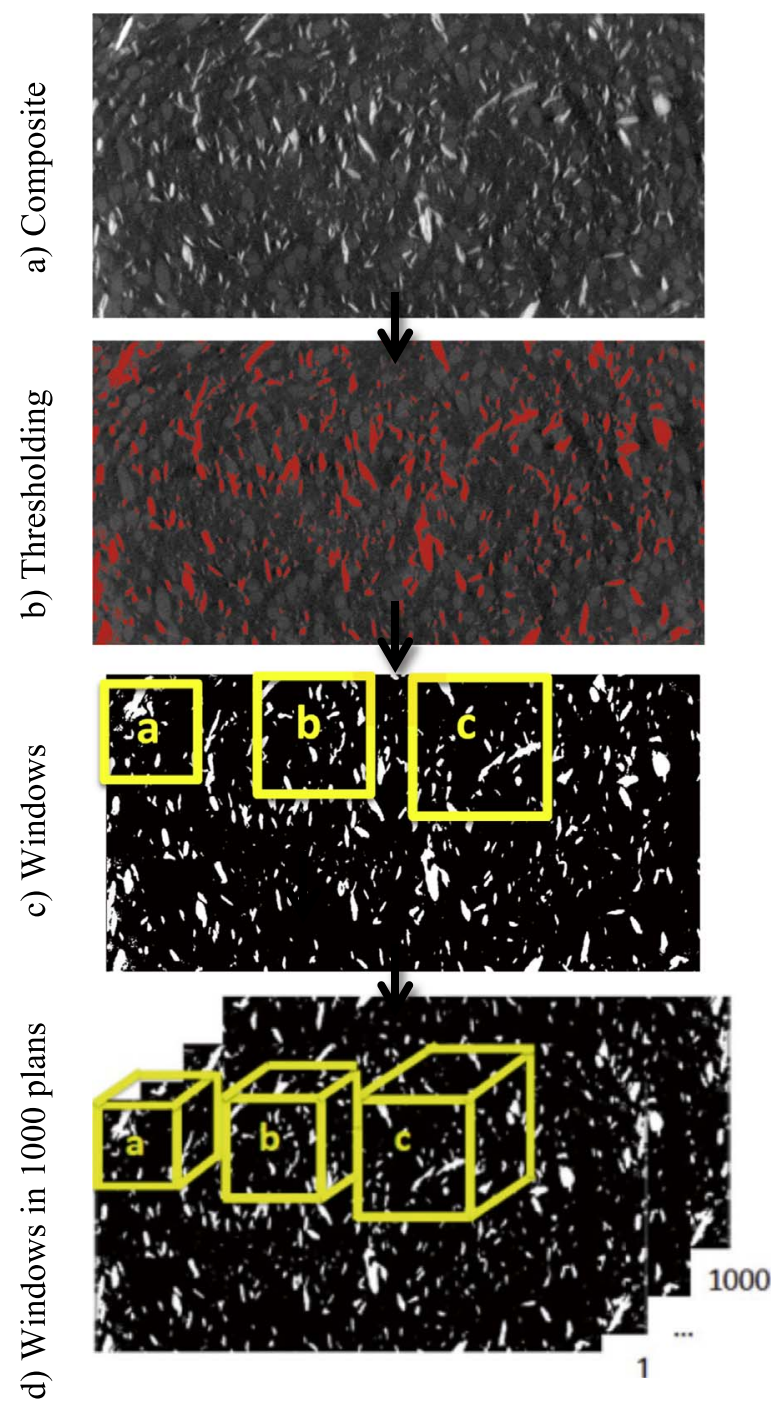

Fig. 3. PGM-HT X-ray tomography image. (a): 2D thresholding (b) $2 \mathrm{D}$ windowing within each plane (c) and 3D on the 1000 planes (d).

$[\phi$ Fibre $]=\left[\phi\right.$ Fibre $\left.+\phi \mathrm{MoS}_{2}\right]-\left[\phi \mathrm{MoS}_{2}\right]$

To solve Eq. (1), the following strategy is used. First a thresholding is done only for the $\mathrm{MoS}_{2}$ (white); and second, it is done for both " $\mathrm{MoS}_{2}$
Table 1

Volume fraction $(\phi)$ of the components of each composite; obtained experimentally (Exp.) and bibliographically (Bib.) [4,10]. "N.A." means that the value is not known.

\begin{tabular}{|c|c|c|c|c|}
\hline & & & Duroid & PGM-HT \\
\hline \multirow[t]{6}{*}{$\phi(\%)$} & Exp. & $\phi$ Fibre & $19 \pm 2$ & $24 \pm 4$ \\
\hline & & $\phi \mathrm{MoS}_{2}$ & $18 \pm 2$ & $10 \pm 2$ \\
\hline & & $\phi$ PTFE & $63 \pm 4$ & $66 \pm 6$ \\
\hline & Bib. & $\phi$ Fibre[4,10,11] & $\sim 14$ & N.A. \\
\hline & & $\phi \operatorname{MoS}_{2}[4,10,11]$ & $\sim 8$ & N.A. \\
\hline & & фPTFE[4] & $\sim 78$ & N.A. \\
\hline
\end{tabular}

+ Fibre". Then the volume fraction of the fibre is obtained by applying the expression (1). Results found by X-ray tomography for the composites of volume fraction, of $\mathrm{MoS}_{2}$ and fibres, are presented in Table 1.

\subsection{Observations by Scanning Electron Microscopy (SEM)}

For the observation of the composites by SEM, samples are cut perpendicularly to the axis of the cylinder, at room temperature. Then, the surfaces generated after cutting are observed in a SEM FEI, XL30 (see Fig. 4).

It is observed by SEM that fibres of RT/Duroid 5813 showed smaller diameter $(\sim 3 \mu \mathrm{m})$ compared to PGM-HT $(\sim 30 \mu \mathrm{m})$ (see Table 1). It is also possible to observe with SEM images that the composites have a limited degree of porosity (this is a qualitative result since the degree of porosity is not quantified). This result is in agreement with the hypothesis made for the determination of volume fraction. Similarly, the length of the fibres is longer for RT/Duroid $5813(>100 \mu \mathrm{m})$ than for PGM-HT $(<100 \mu \mathrm{m})$. Regarding $\mathrm{MoS}_{2}$ particles, for RT/Duroid 5813 their size is estimated to be about $10 \mu \mathrm{m}$ while for PGM-HT, it is about $100 \mu \mathrm{m}$.

\subsection{Experimetal synthesis}

After SEM analysis, it is possible to observe that the fibres of RT/ Duroid 5813 are thinner and longer than those of PGM-HT. The length of fibres for PGM-HT is of about 20-80 $\mu$ m, while for RT/Duroid 5813, it is longer than $100 \mu \mathrm{m}$, and they can even reach the 200 or $300 \mu \mathrm{m}$. Moreover, it is not particularly observed a preferential orientation of the fibres. According to the results obtained from image analysis, it is also possible to discern the volume fraction of the components of PGMHT, so far unknown. It can be said that this approach based on morphological observations can be applied to other self-lubricating 
(a) RT/Duroid 5813

(b) PGM-HT

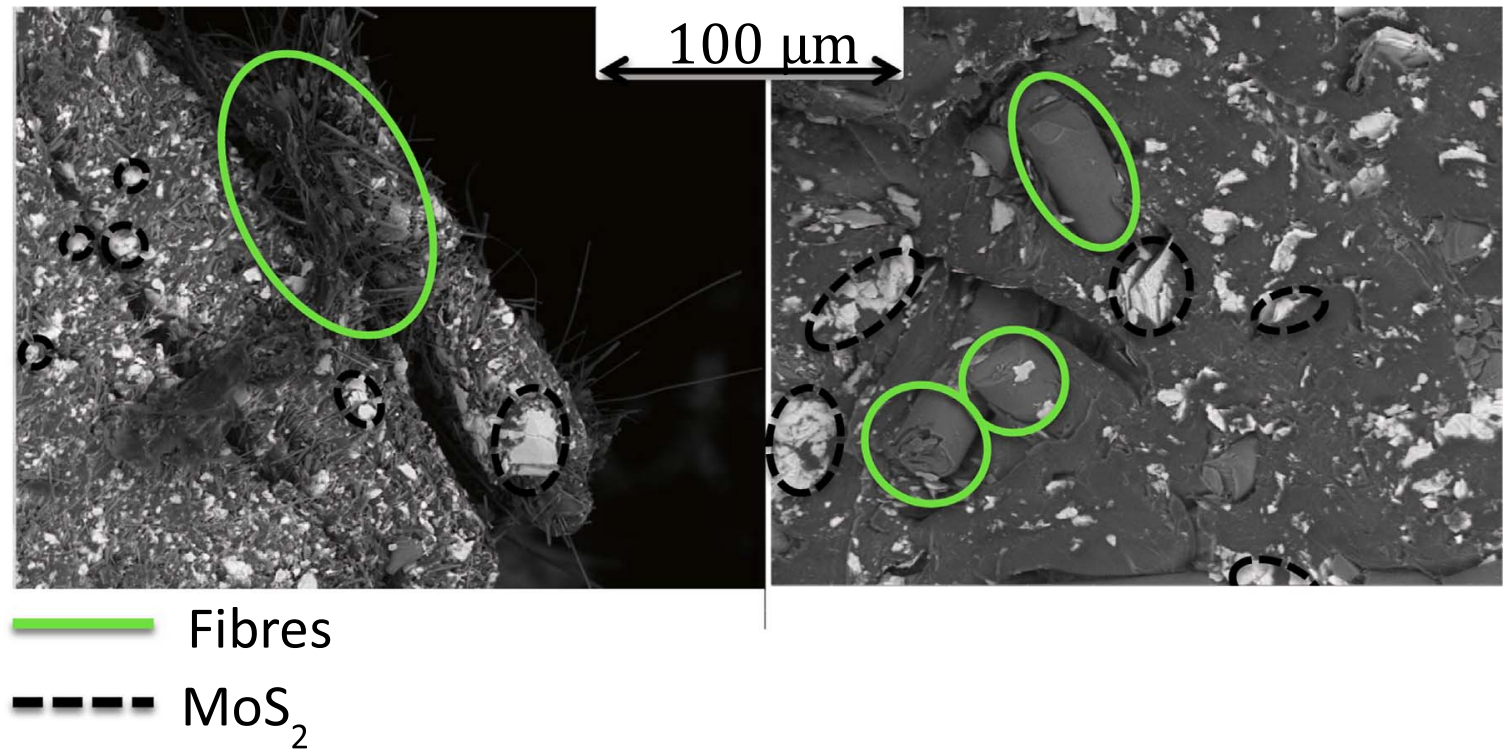

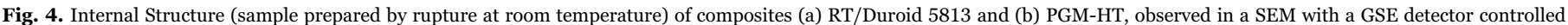
pressure.

composites; for example, to those developed by the European Space Agency (ESA) and Aerospace and Advanced Composites GmbH (AAC) proposed as candidates to replace RT/Duroid 5813 [1].

\section{Discrete element framework}

\subsection{Strategy}

Modelling the double transfer process is a hard task due to its complexity. Indeed, one should be able to represent the whole mechanism (i.e. the bearing and its solicitations), the degradable composite material and the evolution of debris in the system. If an accurate simulation of such a process is complex, it is possible to have a local approach to propose more realistic scenario of contact mechanisms. The Discrete Element framework appears as the most appropriate tools to describe third body flows [12] (from material degradation to wear). Such numerical approach is already used in the context of $\mathrm{C} / \mathrm{C}$ composites $[7,8]$, and in this work it is proposed to extend it for self-lubricated composites. The main idea of the numerical approach is presented on the Fig. 5.

In a first approach, a single contact is considered and one focus on an elementary volume of the cage/ball contact discretized by circular rigid elements. Interaction laws connecting elements, confer to the whole volume a continuous feature. When rigid elements are used as discretization elements, the physical behaviour of the system depends only on the particle interaction law. As local deformations of the bodies are not taken into account, contact laws control the evolution and the rheology of the media, and must be selected in agreement with the behaviour of the real medium [12].

\subsection{Element interaction}

In a first approach, to minimize the number of parameters, a homogenization-like procedure is performed to determine the interaction law. The main idea is not to represent the different components of the material, but to connect the component properties to the interac-

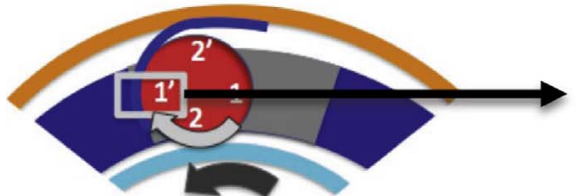

(a)

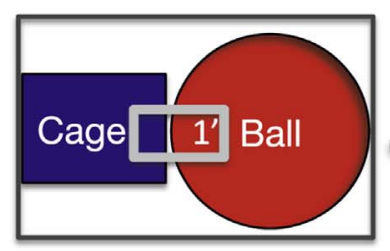

(b)

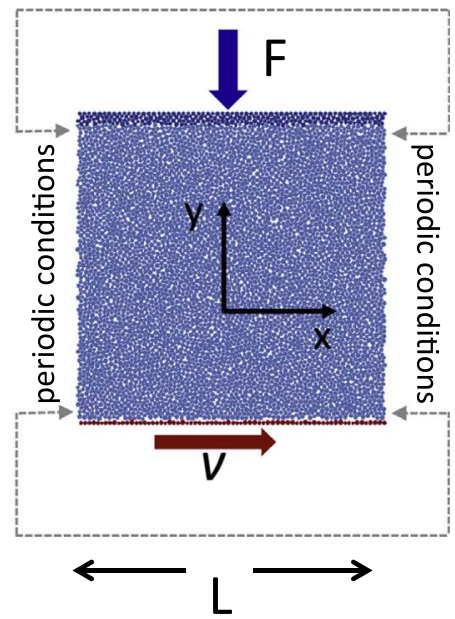

(c)

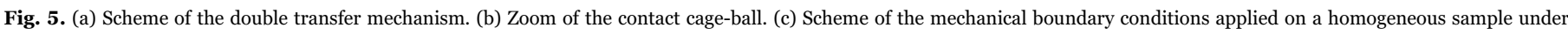

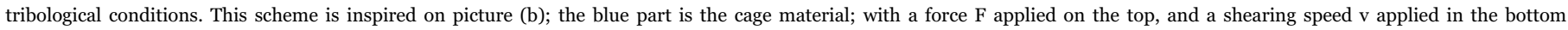
representative of the speed of the ball. 


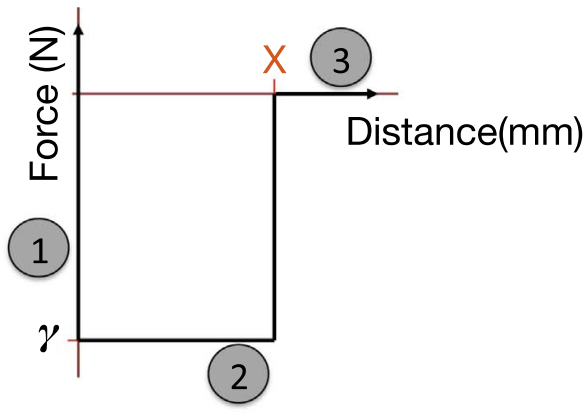

(a)

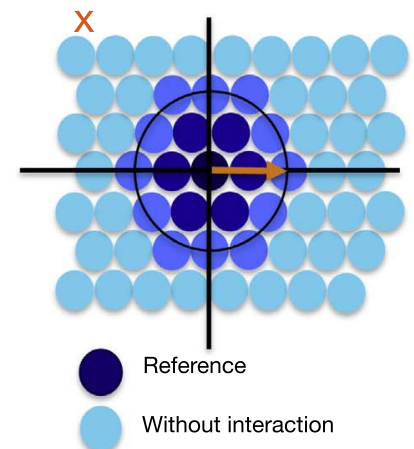

(b)

Fig. 6. (a) - Representative chart of the Interaction law used. (b) - Interaction of the particules at a distance $x=$ d.

tion law parameters. As a result, a specific law based on two parameters is used (see Fig. 6). These two parameters are the distance of attraction $\boldsymbol{x}$, that defines the attraction area of each element, and the attraction intensity force $\gamma$, that represents the constant force in opposition to element separation. With these parameters it is envisaged to represent the plastic deformation of the materials.

In order to explain the chart of Fig. 6-a, the reacting force between two particles will be represented as " $F$ ", and the distance between the particles as "g". If element attraction areas do not overlap, there is no interaction between elements $(\mathrm{F}=0$ and $\mathrm{g}>\boldsymbol{x})$, as shown in zone 3 of Fig. 6-a. If element attraction areas do overlap, and the gap "g" between the bodies is not equal to zero; an attraction force equal to $\gamma$ acts on each element $(\mathrm{F}=\boldsymbol{\gamma}$ and $0<\mathrm{g}<\boldsymbol{x}$ ), as shown in zone 2 of Fig. 6 -a (this constant variation of the force as a function of the distance is tested as a first approach in order to evaluate its suitability). Finally, if the distance between elements is equal to zero $(g=0)$, a repulsive force acts on each element to avoid penetration, as shown in zone 1 of Fig. 6-a. Changing the value of $\boldsymbol{x}$ will be suitable to reproduce longer or shorter interaction within the bulk of the material and thus can be directly connected to fibre length. Changing the value of $\gamma$, will change the ability of the material to be deformed and can be related to plastic property of the composite. Thus, with the combination of these two parameters it is envisaged to build numerical samples, to deform them under compression and tribological tests, and then make an analogy between the plasticity of these numerical samples and the plasticity of the selflubricating composites with long and short fibre length.

\subsection{Equivalent behaviour}

To observe the global behaviour of a medium managed by the previous interaction law, a compression test on a circular sample is performed. The sample diameter $\left(\mathrm{d}_{\mathrm{s}}\right)$ is equal to $0.1 \mathrm{~mm}$ and is discretized with 1000 elements. The sample is compressed until reach a deformation of $25 \%$ (see Fig. 7-a). Four different values of $\boldsymbol{x}$ are tested: $\boldsymbol{x}_{\mathbf{1}}=\mathrm{d} / 20 ; \boldsymbol{x}_{\mathbf{2}}=\mathrm{d} / 10 ; \boldsymbol{x}_{\boldsymbol{3}}=\mathrm{d}$ and $\boldsymbol{x}_{\mathbf{4}}=2 \mathrm{~d}$; where "d", is the diameter of the discretization element (not to be confused with the diameter " $\mathrm{d}_{\mathrm{s}}$ " of the circular sample. The sample is made of a collection of elements of diameter equal to $d$ (see Fig. 7-b)). The influence of the cohesion parameter has been also studied: $\mathbf{Y}_{\mathbf{1}}=\gamma / 2, \mathbf{Y}_{\mathbf{2}}=\gamma, \mathbf{Y}_{\mathbf{3}}=2 \gamma$ where $\boldsymbol{\gamma}=1.5 \mathrm{e}-2 \mathrm{~N}$. In Figs. 7-b and 8 are shown the effects of varying the parameters $\boldsymbol{x}$ and $\boldsymbol{\gamma}$ after compressing the samples. For Fig. 7-b, particle's colour indicates their displacements: light blue particles are in transition between the small displacements (dark blue particles), and high displacements (red particles).

In Fig. 7, the influence of changing the values of the two parameters of the law is studied. After compression tests, it is observed that for higher values of $\boldsymbol{x}(\boldsymbol{x}=2 \mathrm{~d}$ and $\boldsymbol{x}=\mathrm{d})$, the sample tends to deform maintaining an integrity of the interaction between the elements; while for smaller values of $\boldsymbol{x}(\boldsymbol{x}=\mathrm{d} / 10$ and $\boldsymbol{x}=\mathrm{d} / 20)$, the interactions between particles tend to be broken (see Fig. 7-b). It is also possible to study the effect of the two parameters on the hydrostatic pressure supported by the material (see Fig. 8). At a constant value of $\boldsymbol{x}$, the samples will be more resistant to be compressed if the $\gamma$ parameter is higher. Likewise, at a constant value of $\gamma$ if the distance $\boldsymbol{x}$ is higher $(\boldsymbol{x}=2 \mathrm{~d}$ and $\boldsymbol{x}=\mathrm{d}$ ); samples will also resist to higher compressions. Nevertheless, very similar values of pressure are observed for $\boldsymbol{x}=d / 10$ and $\boldsymbol{x}=d / 20$.

\section{Tribological sollicitation}

\subsection{Model descriptions}

After carrying out the study of the parameters of the law, tribological tests are performed. To do so, a value of the parameter $\mathbf{\gamma}=1.5 \mathrm{e}-2 \mathrm{~N}$ is selected after plotting a classical stress-strain curve (see Fig. 9). In this curve it is possible to observe a plateau that can be related to a plastic deformation. A value of $\gamma=1.5 \mathrm{e}-2 \mathrm{~N}$ is considered to be appropriate because with it, the plateau is found in the same order of magnitude that the plateau of PTFE [13,14]. Once the value of $\mathbf{Y}$ is chosen, four values of " $x$ " are tested. For a same volume fraction of the components, a composite having a finer morphology of the fibres (e.g.: small diameter and long fibres) will have a longer zone of contact between the fibre and the rest of the material; therefore, a higher value of " $\boldsymbol{x}$ " might be representative of having a finer composite.

The simulated system is two-dimensional (see Fig. 5, and see simulation parameters in Table 2). The sample is composed of 4900 rigid particles. A small size polydispersity of $20 \%$ is considered in order to prevent crystallization effect in the discretization [15]. The material is sheared between two parallel rough walls, of length $\mathrm{L}$, distant from $\mathrm{L}$. Periodic boundary conditions are applied along the shear direction (lateral boundaries): No particles get out of the contact (wear flow is equal to zero). The wall's roughness is made with a set of grains with the same size polydispersity than the sample discretization. The upper wall, summited to a pressure $\mathrm{P}$ (see values in Table 2), is connected to the packing with the same interaction law that the material (see Section 5.2). The lower wall moves with a constant speed $v$, and interacts with the packing according to the unilateral cohesive law, with Coulomb friction.

\section{Numerical results and discussion}

\subsection{Displacement of the particles}

The total height of the samples is divided in layers of the same height in order to analyze the displacement profile. A number of 40 layers is chosen, because it compromises the ratio between the height of the sample and the discrete element size. The layer number 40 being the furthest layer to the shearing wall (which means, $100 \%$ of the height). The average displacement in the " $\mathrm{x}$ " direction; " $\mathrm{d}_{\mathrm{x}}$ ", is 


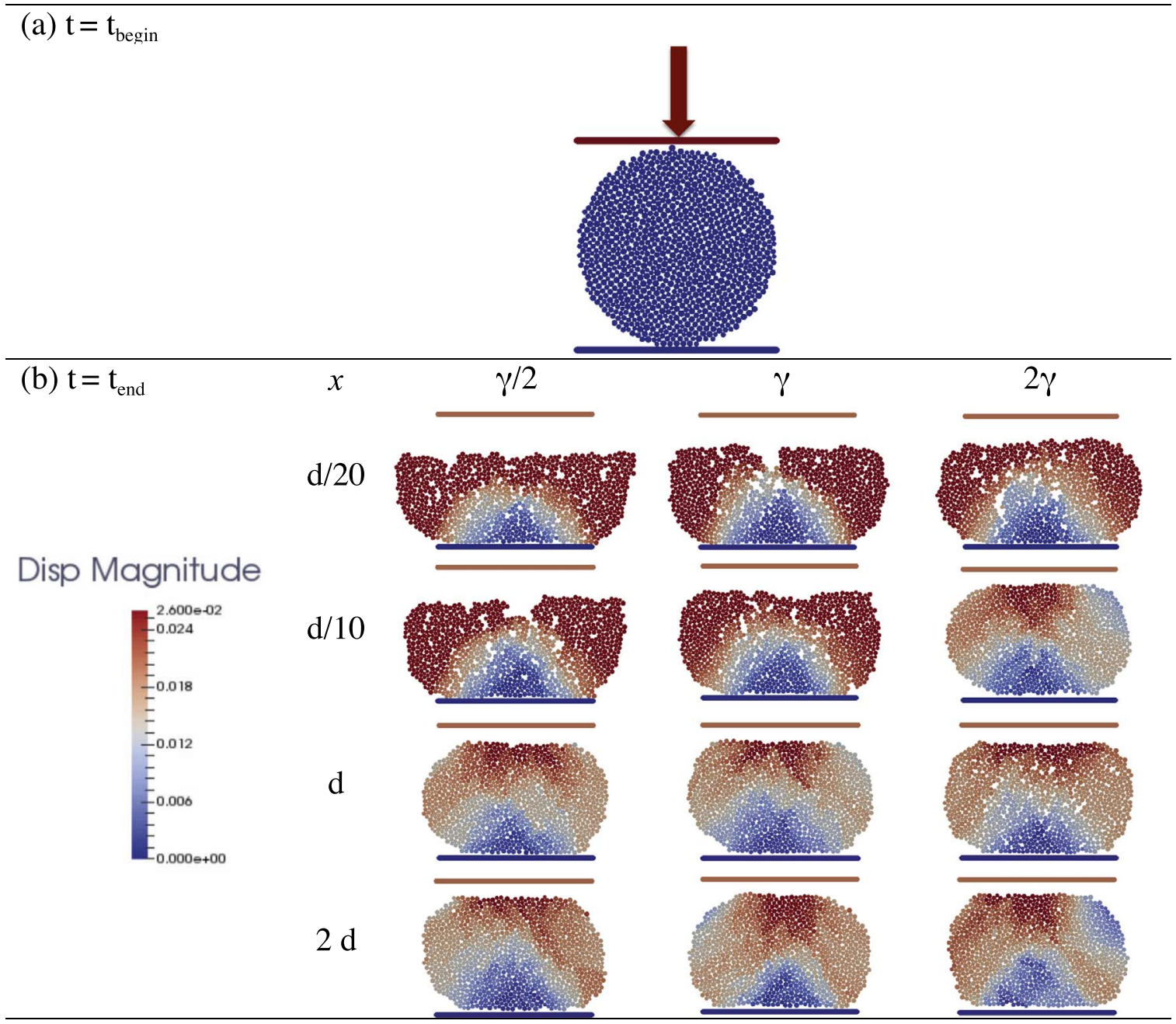

Fig. 7. Compression of a sample until a deformation of 25\%. (a) Sample before compression. (b) Sample after compression.

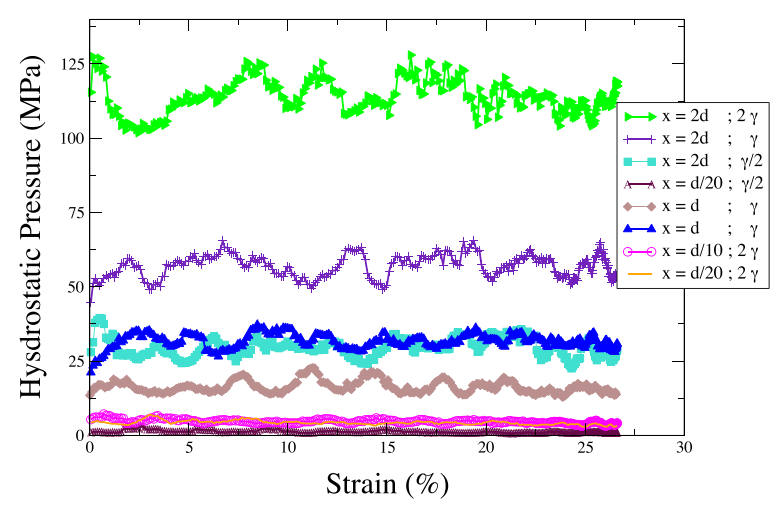

Fig. 8. Influence of the $\gamma$ and $x$ parameter on a sample volume under compression.

calculated for each layer after shearing (see Figs. 10-a and -b); thus, it is possible to observe the sample deformation through it thickness.

It is observed that samples with a smaller distance of attraction, tend to have higher deformations when sheared $(\boldsymbol{x}=\mathrm{d} / 20$ and $\boldsymbol{x}=\mathrm{d} /$ 10). To the contrary, samples with a higher distance of interaction do not present such behaviour (curves blue and red). In this last case, the sample barely deforms when it is sheared. Previously, it is mentioned that a higher value of $\boldsymbol{x}$ might be representative of having a finer composite. In fact, the behaviour for bigger values of $\boldsymbol{x}$ can be explained in the following way: once the distance between particles is longer, a complex network and a dense linkage of interactions is created in the

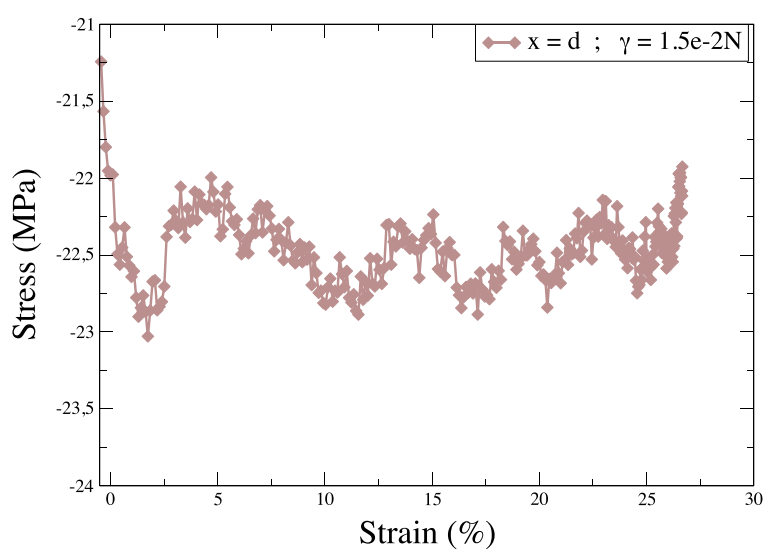

Fig. 9. Stress-strain curve for a sample with $\boldsymbol{x}=\mathrm{d}$ and $\gamma=1.5 \mathrm{e}-2 \mathrm{~N}$, under compression.

material. This network might not only make harder the deformation of the material when it is sheared, it also might promote the entrapment of fibres. This behaviour is confirmed in literature for the tribological behaviour of the composites with finer morphologies [2].

For tests with a smaller pressure (see Fig. 10-a), the sample is sheared in the whole thickness (excepted for $\boldsymbol{x}=2 \mathrm{~d}$, where the deformation is quasi-equal to 0). For tests with a higher pressure the behaviour is really different, presenting a localization within the thickness. The upper half of the sample is not deformed while the lower part is plastically deformed, with longer deformations than for 
Table 2

Simulation parameters (nominal values).

\begin{tabular}{ll}
\hline Average particle diameter (d) & $3 \mathrm{e}-3 \mathrm{~mm}$ \\
\hline Polydispersity & $20 \%$ \\
Sample Height (L) & $0.2 \mathrm{~mm}$ \\
Sample Length (L) & $0.21 \mathrm{~mm}$ \\
Pressure (P) & $7 \mathrm{MPa}, 70 \mathrm{MPa}$ \\
Velocity (V) & $2 \mathrm{~mm} / \mathrm{ms}$ \\
Time step (dt) & $2 \mathrm{e}-6 \mathrm{~s}$ \\
Simulation time (t) & $0.16 \mathrm{~s}$ \\
Density ( $\rho)$ & $2.9 \mathrm{e}-6 \mathrm{~g} / \mathrm{mm}^{3}$ \\
$\gamma$ & $1.5 \mathrm{e}-2 \mathrm{~N}$ \\
Distance of attraction $(x) *$ in mm & $2 \mathrm{~d}, \mathrm{~d}, \mathrm{~d} / 10, \mathrm{~d} / 20$ \\
\hline
\end{tabular}

smaller pressures. Only the higher value of $\boldsymbol{x}$ presents a quasi-null deformation, with the exception of the layers that are close to the contact (sample height $<10 \%$ ). It is also possible to observe that there is a tendency of the particles of $\boldsymbol{x}=\mathrm{d}, \boldsymbol{x}=\mathrm{d} / 10$, and $\boldsymbol{x}=\mathrm{d} / 20$, to converge to a similar displacement. This means that there is a threshold in which the particles of the material start to deform, and this threshold depends on the force applied.

\subsection{Stress profile}

In discrete media, the notion of internal moments is used for the calculation of the stress tensor. These tensors are calculated for the volume of the sample, $v$. They are named $\sigma_{i j}$ and are estimated between two particles $\mathrm{i}$ and $\mathrm{j}$, and for a contact $\alpha$, as follows [16]:

$\sigma_{i j}=\frac{1}{v} \sum_{\alpha=1}^{N_{c}} l_{i}^{\alpha} \otimes r_{j}^{\alpha}$

In which $l$ is the inter-centre vector between the particles, $\mathrm{r}$ is the reaction force at the contact, and $\mathrm{N}_{\mathrm{c}}$ is the total number of contacts. It is possible to calculate these tensors for different areas of the media.

In Figs. 11-a and -b it is shown the distribution of the component $\sigma_{12}$ of the stress tensor for $\mathrm{P}_{\mathrm{a}}=7 \mathrm{MPa}$ and $\mathrm{P}_{\mathrm{b}}=70 \mathrm{MPa}$ respectively. For a smaller pressure all the samples show to be around a same stress value, a quasi-null stress value; and only the higher value of $\boldsymbol{x}$ present a high degree of deviations. Nonetheless, for a higher value of pressure the behaviour is different, the stress increases if the distance of interaction " $\boldsymbol{x}$ " between the particles (equivalent to a longer fibre length) is higher.

For $\boldsymbol{x}=\mathrm{d}, \boldsymbol{x}=\mathrm{d} / 10$, and $\boldsymbol{x}=\mathrm{d} / 20$, the upper half of the samples present a high degree of deviations in the stress profile, while for $\boldsymbol{x}=2 \mathrm{~d}$,

$$
\text { (a) } \mathrm{P}_{\mathrm{a}}=7 \mathrm{MPa}
$$

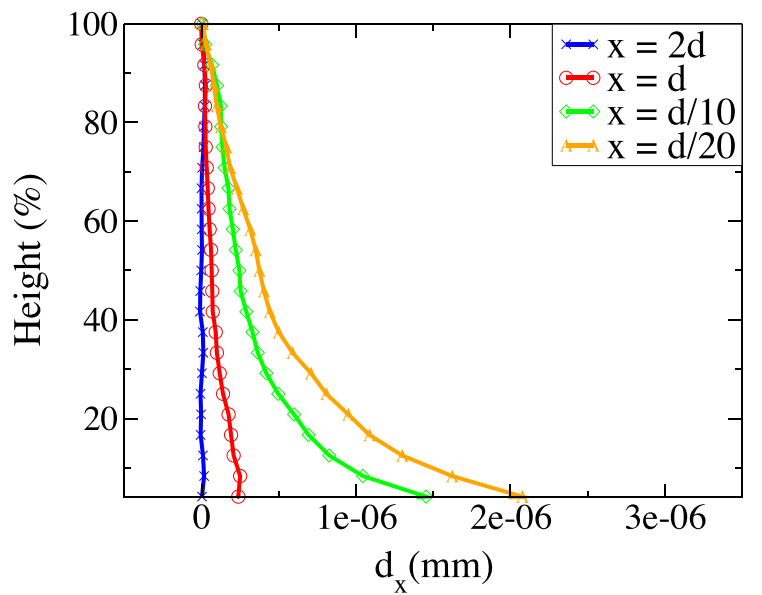

these deviations are marked for a height higher than 20\%. When fibres are longer (higher values of $\boldsymbol{x}$ ), the material resists more to shear process. This resistance creates an action-reaction effect within each layer, which resists to their deformations and increases the deviations in the stress profiles. So, these deviations are related to the resistance of the material to be sheared. For a higher pressure, the deviations are higher in the zones in which the material has a quasi-null deformation (see Figs. 10 and 11).

\section{Conclusions}

This work is focused on the study of the effect of fibre length on the tribological properties of RT/Duroid 5813 and PGM-HT, by a combined experimental/numerical approach. With the experimental observation and image analysis, the purpose is to verify the differences between the composites' microstructures and to study its compositions. With the numerical tests, the objective is to represent these differences of the composites' microstructure numerically, and then analyse the tribological behaviour these materials.

From image analyses by SEM and X-ray Tomography, it is possible to verify a finer and a coarser microstructure for RT/Duroid 5813 and PGM-HT respectively. Then, these finer and coarser microstructures are represented by DEM, by a homogenization-like interaction law between the elements of interaction. The first parameter of this law, the distance $\boldsymbol{x}$, defines the attraction area of each element and represents the fibre length: the higher $\boldsymbol{x}$, the higher the fibre length. The second parameter, the attraction intensity force $\gamma$, represents the constant force in opposition to element separation.

The influence of changing the values of the two parameters of the law is also studied. After compression tests, higher values of $\boldsymbol{x}(\boldsymbol{x}=2 \mathrm{~d}$ and $\boldsymbol{x}=\mathrm{d}$ ), the sample tended to deform maintaining an integrity of the interaction between the elements; while for smaller values of $\boldsymbol{x}(\boldsymbol{x}=\mathrm{d} /$ 10 and $\boldsymbol{x}=\mathrm{d} / 20$ ), the interactions between particles tended to be broken. Nevertheless, after shearing (with a pressure on the top of the sample), it is observed that samples with a higher distance of interaction particles barely deform; meanwhile, samples with a smaller distance of attraction, tend to have higher deformations.

A higher value of $\boldsymbol{x}$ represents a finer composite. When the distance " $\boldsymbol{x}$ " between particles is longer, a dense and complex network of interactions is created in the material. If this network is compressed it is able to maintain its integrity. If this network is sheared, it will not be easily deformed. Nevertheless, when the distance " $\boldsymbol{x}$ " between particles is smaller this network will be less dense. As a result, the interactions will be more vulnerable to be broken, and if the material is sheared, elements will be freer to move. In consequence, a denser

(b) $\mathrm{P}_{\mathrm{b}}=70 \mathrm{MPa}$

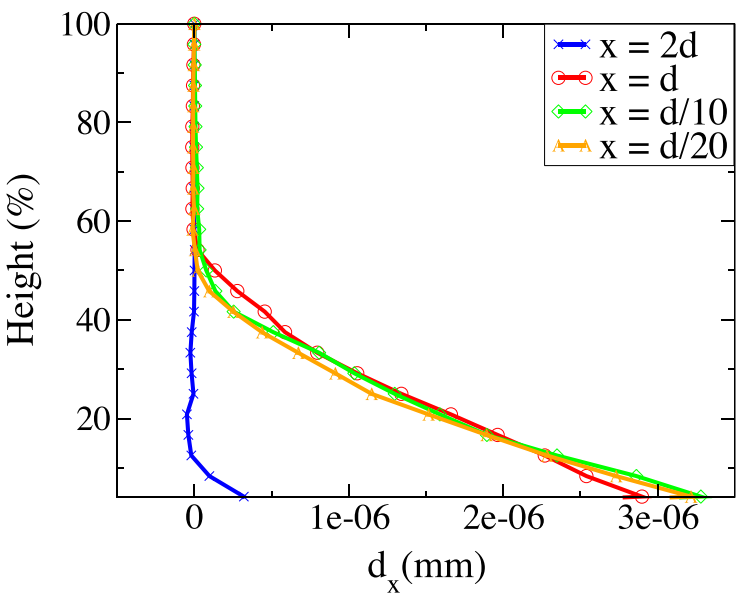

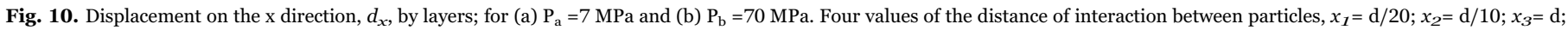
$x_{4}=2 \mathrm{~d}$ are tested. 
(a) $\mathrm{P}_{\mathrm{a}}=7 \mathrm{MPa}$

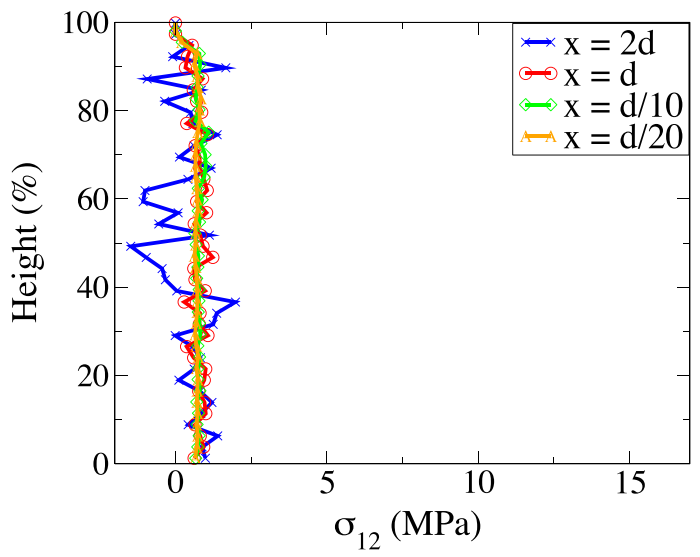

(b) $\mathrm{P}_{\mathrm{b}}=70 \mathrm{MPa}$

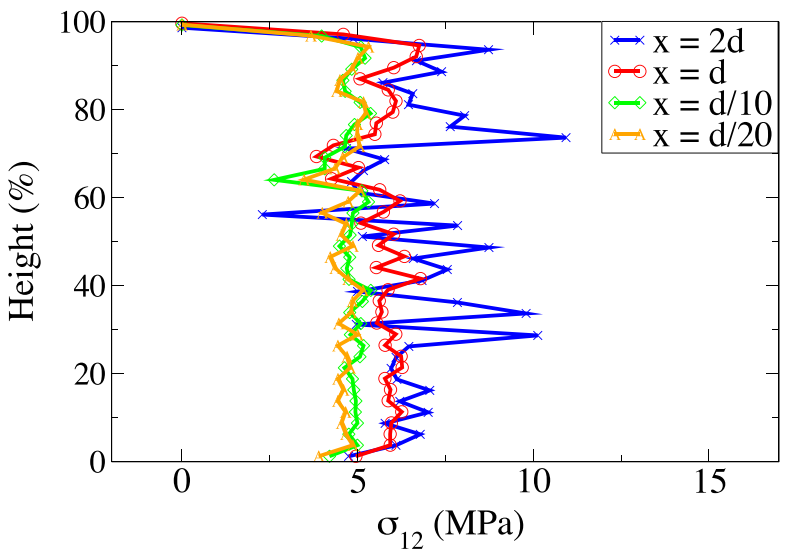

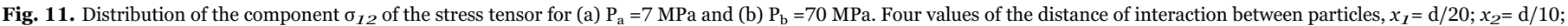
$x_{3}=\mathrm{d} ; x_{4}=2 \mathrm{~d}$ are tested.

network in which a linkage of interactions is created also fosters the entrapment of fibres. This behaviour is confirmed in literature for the tribological behaviour of the composites with finer morphologies [2].

Summarising all results, it can be concluded that a combined experimental/numerical approach with DEM, it is a suitable approach that permits not only the understanding, but also it shows to be a promising tool to predict the tribological behaviour of the selflubricating composites.

\section{Future work}

To confirm the results and go further in the study, both mechanical and adhesion properties of these materials obtained are currently under study (STLE. Saulot et al., 2016). Additionally, it is envisaged in further work to study also by DEM the wear of these materials.

\section{Acknoledgements}

The authors would like to thank CNES and SKF for supporting the study.

\section{References}

[1] A. Merstallinger, C. Macho, G. Brodowski-Hanemann, H. Bieringer, SLPMC - new self lubricating polymer matrix composites for journal and ball bearing applications in space, ESMATS, Bilbao, Spain, 2015, p. 8.

[2] G. Colas, A. Saulot, S. Descartes, Y. Michel, Y. Berthier, Double transfer experiments to highlight design criterion for future self-lubricating materials, ESMATS,
Bilbao, Spain, 2015, p. 8.

[3] J. Sicre, Y. Michel, E. Videira, L. Nicollet, D. Baud, PGM-HT as DUROID 5813 replacement? Lifetime results on STD scanning earth sensor and polder bearing shaft, ESMATS, Vienna, Austria, 2009, p. 8.

[4] Lockheed Missiles and Space Company, Space materials handbook, AddisonWesley Publishing, Sunnyvale California, USA., 1965.

[5] C. Macho, A. Merstallinger, G. Brodowski-Hanemann, M. Palladino, L. Pambaguian, SLPMC - self lubricating polymer matrix composites, ESMATS, The Netherlands, 2013.

[6] Gras R, Mondelli R, Pappalettere C, Quarta V. Study of Solid Lubrication of Rolling Bearings in Cryogenic Environment, X International Congress \& Exposition on Experimental \& Applied Mechanics, Costa Mesa, USA; 2004.

[7] Champagne M, Renouf M, Berthier Y. Modeling Wear for Heterogeneous Bi-Phasic Materials Using Discrete Elements Approach. vol. 136, no. 021603, pp. 1-11; 2014.

[8] J. Riviere, M. Renouf, Y. Berthier, Thermo-mechanical investigations of a tribological interface, Tribol Lett 58, Springer Verl., 2015, pp. 48-59.

[9] Ferreira T, Rasband W. Image J. User Guide. ImageJ/Fiji 1.46, 10-Feb-; 2012.

[10] SODERN, Amélioration de la Lubrification Seche Definition et Recette des Roulements. Internal Document (In French), SODERN; 1996.

[11] G. Colas, A. Saulot, T. Quercia, C. Godeau, E. Régis, S. Descartes, Y. Berthier, Analyse tribologique préliminaire de la formation d'un double transfert par des matériaux autolubrifiants pour application spatiale en liaison avec la thèse de G. Colas, INSA Lyon, Lyon, France, 2015.

[12] M. Renouf, H.-P. Cao, V.-H. Nhu, Multiphysical modeling of third-body rheology, Tribol Int 44 (2011) 417-425.

[13] P.J. Rae, D.M. Dattelbaum, The properties of poly(tetrafluoroethylene) (PTFE) in compression, Polymer 45 (2004) 7516-7625.

[14] Pont Du, Teflon PTFE.Properties Handbook. USA

[15] Lätzel M, Luding S, Herrmann HJ. From discontinous models towards a continuum description. In: Vermeer PA, Diebels S, Ehlers W, Herrmann HJ, Luding S, Ramm E. (editors). Continous and Discontinous Modelling of Cohesive-Frictional Materials. in Lecture Notes in Physics, 2001, vol. 568, p. 215

[16] F. Radjaï, F. Dubois, Discrete modeling of granular materials, Wiley, London, UK. 2011. 